\title{
The effectiveness of primary antibiotic therapy in the treatment of acute appendicitis Sopuev A. ${ }^{1}$, Tutashev A. ${ }^{2}$, Kudajberdiev Z. ${ }^{3}$, Kalzhikeev A. ${ }^{.4}$ Sydygaliev K. ${ }^{5}$ Эффективность первичной антибиотикотерапии при лечении острого аппендицита \\ Сопуев А. А. ${ }^{1}$, Туташев А. С. ${ }^{2}$, Кудайбердиев 3. К. $^{3}$, Калжикеев А. М. ${ }^{4}$, Сыдыгалиев К. С. ${ }^{5}$

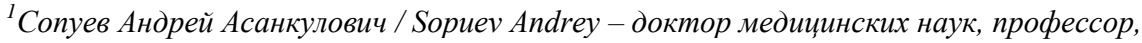 \\ заведуюший кафедрой, \\ кафедра госпитальной хирургии, Кыргызская государственная медииинская академия; \\ ${ }^{2}$ Tуташев Айбек Сырдашбекович / Tutashev Aibek - врач-ординатор; \\ ${ }^{3}$ Кудайбердиев Зиявидин Кубанычбекович / Kudaiberdiev Ziyavidin - врач-ординатор, Национальный хирургический \\ иентр; \\ ${ }^{4}$ Калжикеев Абдрасул Мусатаевич / Kaljikeеv Abdrasul - доктор медицинских наук, доиент; \\ ${ }^{5}$ Сыдыгалиев Кыльчбек Сулкайдарович / Sydygaliev Kylychbek - доктор медицинских наук, дочент, \\ кафедра госпитальной хирургии, \\ Кыргызская государственная медицинская академия, г. Бишкек, Кыргызская Республика
}

Аннотация: в работе проведен анализ доступных научных исследований по оценке эффективности антибактериальной терапии как основного метода лечения острого аппендицита.

Abstract: the analysis of the available research on the effectiveness of antibiotic therapy as primary treatment of acute appendicitis.

Ключевые слова: аппендицит, аппендэктомия, антибиотики, мета-анализ.

Keywords: appendicitis, appendectomy, antibiotics, meta-analysis.

Острый аппендицит (ОА) является наиболее частой причиной острого живота. В США встречаемость ОА составляет от 250000 до 280000 случаев в год. В стационарах США на ОА приходится более миллиона койко-дней в году с финансовыми затратами на более чем 3 миллиарда долларов ежегодно. На протяжении более 100 лет при ОА проводят хирургическое вмешательство в виде аппендэктомии. Уровень смертности при ОА колеблется на довольно низких цифрах от 0,07 до 0,7 \% [1]. Тем не менее, хирургическое вмешательство связано с выраженным болевым синдромом, возможностью развития грыжи, кишечной непроходимости, венозной тромбоэмболии, сердечно-легочных осложнений и увеличения финансовых расходов.

В пятидесятых годах XX века была предпринята попытка разработки нехирургического лечения острого аппендицита, однако эта идея в те годы не получила поддержки [2]. В этом смысле, антибактериальная терапия неосложненного острого аппендицита может быть связана со снижением затрат на лечение, избеганием операции и ее последующих осложнений.

Поэтому целью данного исследования является обзор доступных научных исследований по оценке эффективности антибактериальной терапии как основного метода лечения при неосложненном остром аппендиците.

\section{Материал и методы исследования}

В исследование включены ретроспективные, перспективные и экспериментальные исследования по оценке эффективности первичной антибиотикотерапии при неосложненном остром аппендиците у взрослых по сравнению с аппендэктомией.

Неосложненный острый аппендицит определялся как стадия развития острого воспаления червеобразного отростка без флегмонозно-гангренозных изменений, перфораций и перитонита.

Всего подверглись аналитической обработке 8 мета-анализов [3-10], общие характеристики которых приведены в таблице 1. Среднее число объединенных в пул пациентов, включенных в каждый мета-анализ, было равно $862 \pm 211$. Доля больных, получивших первичную антибактериальную терапию, равнялась в среднем $403 \pm 74$, доля больных, которым была произведена аппендэктомия, равнялась $458 \pm 163$.

Таблииа 1

Характеристика научных исследований, включенных для анализа эффективности первичной антибиотикотерапии при лечении $O A$

\begin{tabular}{|l|l|l|l|l|l|}
\hline \multirow{2}{*}{$№$} & \multirow{2}{*}{ Автор, год } & \multicolumn{2}{|l|}{ Больные } & \multirow{2}{*}{ Дизайн исследования } \\
\cline { 3 - 5 } & Всего & A & S & РКИ \\
\hline 1. & $\begin{array}{l}\text { Varadhan et al. (2010) } \\
{[13]}\end{array}$ & 661 & 350 & 311 & (20 \\
\hline
\end{tabular}




\begin{tabular}{|l|l|l|l|l|l|}
\hline 2. & Liu et al. (2011) [14] & 1201 & 433 & 768 & РКИ Наблюдательное \\
\hline 3. & $\begin{array}{l}\text { Ansaloni et al. (2011) } \\
{[15]}\end{array}$ & 741 & 390 & 351 & РКИ \\
\hline 4. & Wilms et al. (2011) [16] & 901 & 415 & 486 & РКИ \\
\hline 5. & Mason et al. (2012) [17] & 980 & 510 & 470 & РКИ \\
\hline 6. & $\begin{array}{l}\text { Varadhan et al. (2012) } \\
{[18]}\end{array}$ & 900 & 470 & 430 & РКИ \\
\hline 7. & Liu et al. (2014) [19] & 983 & 391 & 592 & РКИ \\
\hline 8. & Kirby et al. (2015) [11] & 531 & 268 & 263 & РКИ \\
\hline
\end{tabular}

\section{Результаты}

Первичная антибиотикотерапия ОА была связана со значительным снижением частоты различных менее и более серьезных осложнений в большинстве исследований (раневая инфекция, длительный послеоперационный период, диарея, анаэробная неклостридиальная инфекция, грибковая инфекция, абсцессы брюшной полости, перитонит, кишечная непроходимость, послеоперационные сердечные и легочные осложнения).

Медикаментозное лечение ОА было связано с более быстрым восстановлением после воспалительного процесса. Это определялось путем оценки динамики изменений температуры тела, количества нейтрофилов и уровня С-реактивного белка (СРБ). Кроме этого, у пациентов с первичной антибиотикотерапией $\mathrm{OA}$ имел место более короткий период болевого синдрома и уменьшение применения обезболивающих препаратов. У больных этой группы сроки возвращения к трудовой деятельности сократились в среднем до 5,2 суток $(\mathrm{p}<0,001)$, а сроки пребывания в стационаре также сократились в среднем до 0,19 суток. В течение последующего одного года наблюдений не было обнаружено каких-либо существенных различий между обоими группами пациентов (10,6\% в сравнении c $9,3 \% ; \mathrm{p}=$ NS) [11].

С другой стороны, первичная антибиотикотерапия была связана с более высокой частотой повторной госпитализации, которая колебалась от 14,2 до $20 \%$. При повторной госпитализации в абсолютном большинстве случаев производилась аппендэктомия, только в нескольких случаях был проведен курс антибиотикотерапии без операции.

В большинстве исследований, длительность пребывания в стационаре существенно не отличалась между двумя группами больных.

\section{Обсуждение}

Результаты проведенного аналитического обобщения серии мета-анализов показали, что первичная антибиотикотерапия неосложненного острого аппендицита связана с меньшим количеством осложнений, с более быстрым восстановлением после воспалительного процесса, с более быстрым купированием болевого синдрома и снижением количества вводимых анальгетиков, со снижением количества нетрудоспособных дней и снижением расходов на лечение и реабилитацию. С другой стороны, консервативная терапия ОА сопряжена с более высокой неэффективностью лечения и более высоким уровнем регоспитализации в сравнении с первичной аппендэктомией.

Лечение аппендицита предполагает понимание острого аппендицита как патологический процесс широкого спектра, ранжированный от легких самопроизвольно разрешающихся случаев (до 20 $\%)$ до аппендиксных перфораций и разлитого перитонита. В этом смысле фактическая задача состоит в том, чтобы отличить тех пациентов, у которых воспалительный процесс имеет возможность разрешиться, от пациентов, у которых будут развиваться осложнения (гангрена, абсцесс, перфорация и перитонит). В некоторых исследованиях попытались определить факторы риска осложненного аппендицита [1]. Основными факторами риска осложненного аппендицита определили некоторые клинические (мужской пол, возраст $\geq 60$ лет возраста и выраженная симптоматика) и лабораторные (лейкоцитоз, повышенный уровень С-реактивного белка и билирубина) факторы.

Обоснованная интерпретация результатов обследования может улучшить диагностику осложненного аппендицита, позволяя избежать консервативного лечения больных с осложненным аппендицитом $[2,11]$.

Для диагностики неосложненного острого аппендицита были использованы КТ, УЗИ и клиническое обследование раздельно или в сочетании. КТ при остром аппендиците имеет высокую диагностическую чувствительность и специфичность, повышая показания к аппендэктомии, особенно у пациентов с низкой шкалой Альварадо. Использование комбинированных клинических показателей (шкала Альварадо и шкала аппендикулярной воспалительной реакции) в сочетании с рациональным использованием методов визуализации (т. е. не рутинное использование КТ или УЗИ в большинстве случаев) показало диагностическую точность, соотносительную применению КТ для диагностики острого аппендицита [1]. 
Процент успешной первичной антибиотикотерапии при неосложненном остром аппендиците варьировал от 58,3 до 73,4 \%. Однако 42 \% пациентов с успешной первичной антибиотикотерапией в последующем потребуется аппендэктомия [11]. Первичная антибиотикотерапия больных с неосложненным аппендицитом является безопасной, даже если впоследствии потребуется аппендэктомия [10].

Профилактическое назначение антибиотиков во время аппендэктомии связано с 3-кратным снижением частоты послеоперационной раневой инфекции. Во включенных исследованиях частота послеоперационной раневой инфекции у пациентов, подвергшихся первичной аппендэктомии, составила $2,8 \%$ при использовании антибиотикопрофилактики и 11,8 \% - без использования периоперационной антибиотикопрофилактики. Это могло сформировать уклон в мета-анализах об использовании фактора раневой инфекции в качестве основной конечной точки, так как исследования, которые не использовали профилактическое назначение антибиотиков, могли быть переориентированы в пользу первичной антибиотикотерапии $[11,12]$.

Открытая аппендэктомия, хотя и применяется повсеместно, связана с более продолжительным болевым синдромом и применением анальгетиков, с более длительным периодом нетрудоспособности и нахождения в стационаре, а также с более высокой активностью раневой инфекции по сравнению с лапароскопической аппендэктомией [2]. В представленных исследованиях в большинстве случаев были представлены случаи открытых аппендэктомий. Это, возможно, способствовало значительным различиям в уровне болевого синдрома и объемах применения анальгетиков, в длительности заболевания и периода нетрудоспособности, в частоте возникновения раневой инфекции между группами больных с первичной антибиотикотерапией и с произведенной аппендэктомией.

Таким образом, аппендэктомия считается золотым стандартом в лечении острого аппендицита. Тем не менее, у пациентов с неосложненными формами острого аппендицита и отсутствием различных прогностических факторов риска применение первичной антибактериальной терапии может быть безопасным и эффективным. Решение о первичной антибактериальной терапии пациентов с острым несложным аппендицитом должно приниматься на индивидуальной основе. Больные этой категории должны находиться под тщательным наблюдением в течение всего периода лечения.

\section{Лuтература}

1. Рехачев В. П. Острый аппендицит. - Архангельск: 2010. - 192 С.

2. Сопуев А. А., Туташев А. С., Калжикеев А. М., Искаков М. Б., Кудайбердиев 3. К. Особенности клиники, диагностики и лечения острого аппендицита у беременных // Проблемы современной науки и образования. - 2016. - № 11 (53). - С. 121-124.

3. Kirby A., Hobson R. P., Burke D., Cleveland V., Ford G., West R. M. Appendicectomy for suspected uncomplicated appendicitis is associated with fewer complications than conservative antibiotic management: a meta-analysis of post-intervention complications. // J. Infect. - 2015. - v. 70. - pp. 105110.

4. Varadhan K. K., Humes D. J., Neal K. R., Lobo D. N. Antibiotic therapy versus appendectomy for acute appendicitis: a meta-analysis. // World J. Surg. - 2010. - v. 34. - pp. 199-209.

5. Liu K., Fogg L. Use of antibiotics alone for treatment of uncomplicated acute appendicitis: a systematic review and meta-analysis. // Surgery. - 2011. - v. 150. - pp. 673-683.

6. Ansaloni L., Catena F., Coccolini F., Ercolani G., Gazzotti F., Pasqualini E. et al. Surgery versus conservative antibiotic treatment in acute appendicitis: a systematic review and meta-analysis of randomized controlled trials. // Dig Surg. - 2011. - v. 28. - pp. 210-221.

7. Wilms I. M., de Hoog D. E., de Visser D. C., Janzing H. M. Appendectomy versus antibiotic treatment for acute appendicitis. // Cochrane Database Syst Rev. - 2011. - v. 11. - CD008359.

8. Mason R. J., Moazzez. A., Sohn H., Katkhouda N. Meta-analysis of randomized trials comparing antibiotic therapy with appendectomy for acute uncomplicated (no abscess or phlegmon) appendicitis. // Surg Infect (Larchmt). - 2012. - v. 13. - pp. 74-84.

9. Varadhan K. K., Neal K. R., Lobo D. N. Safety and efficacy of antibiotics compared with appendicectomy for treatment of uncomplicated acute appendicitis: meta-analysis of randomised controlled trials. // BMJ. - 2012. - v. 344. - e2156.

10. Liu Z. H., Li C., Zhang X. W., Kang L., Wang J. P. Meta-analysis of the therapeutic effects of antibiotic versus appendicectomy for the treatment of acute appendicitis. // Exp Ther Med. - 2014. - № 7. - pp. $1181-1186$.

11. Мамакеев М. М., Сопуев А.А., Иманов Б. М., Ибраимов Б. А. Антибиотикопрофилактика и антибиотикотерапия мандолом в хирургии (Методические рекомендации): Утв. Мин. здравоохранения КР 20.12.99. - Бишкек, 2000. - 19 с. 
12. Мамакеев М. М., Сопуев А. А., Салибаев О.А. Измерение скорости распространения поверхностных акустических волн в прогнозировании и диагностике течения раневого процесса // Хирургия. Журнал им. Н. И. Пирогова. - 2000. - № 1. - С. 54-55. 